\title{
FOREWORD FROM PRESIDENT ROBERT S. NELSEN
}

The Journal of Transformative Leadership and Policy Studies (JTLPS) is a peer-reviewed Journal sponsored by the California State University Chancellor's Office and the CSU's 16 Education Doctorate programs. As President at Sacramento State, I am pleased to know that Volume 8.1 focuses on mentorship and its impacts on the achievement and success for doctoral students of color. Inclusive Excellence is of paramount importance at Sacramento State and is critical to student success.

The manuscripts included in this volume highlight the important role that mentorship can play in attainment, achievement, and career trajectory for marginalized groups of students. Each one approaches this focus with a different method of analysis and the volume illustrates the importance of fostering organic mentorship opportunities within their doctoral programs.

The articles are written by dedicated educators and educational leadership practitioners. These scholars are driven by their own experiences, as well as those of their students. Their passion to create meaningful change within their institutions, as well as across the country, is evidenced within these carefully constructed articles. The opportunity to hear some of these testimonies adds a unique level of power and depth to this volume.

As educational leaders, we must be willing to evaluate new methods of fostering success, especially for traditionally marginalized students. We must adopt new practices and learn from the successes and failures of other programs. Mentorship is an important tool for training the next generation of leaders in all fields, but as highlighted by these articles, this is particularly true for doctoral students of color.

Sacramento State is both a Hispanic Serving and an Asian Serving Institution, and I am pleased to know that Volume 8.1 focuses on this important and understudied topic. I encourage you to share Volume 8.1 widely with your colleagues and academic communities.

Sincerely,

Robert S. Nelsen

President

California State University, Sacramento 